\title{
Antifungal activity of seven plant extracts against root rot fungi infected cantaloupe plant
}

1- Envi University of Sadat City

Adel S. K. , Sabry I. M. ، Ashraf M. M‘, Saeed Z. K

2-Faculty of Agriculture al-manoufia University

\section{ABSTRACT}

The study dealt with the antifungal activity of some plant extracts against the fungi of mold rot of the roots that infect the roots of the cantaloupe plant, where the affected cantaloupe plant roots were collected from different places in Egypt, including (Nubaria _ Khattaba $\neg-$ Medina Sadat _ Egypt's Desert Road, Desert Road kilo 76) and the Fusarium Solani fungi and fungi were isolated. Lithium - Solanese Resect Fungus, seven wild plants were collected, then plant extracts were made using an organic solvent (methanol) and the results of an antifungal activity experiment showed that all the plant extracts led to a significant inhibition of the growth of the tested fungi. Inhibition against Fusarium solani fungi $52.6 \mathrm{~mm}$ and against fungicide solani fecunda $22.2 \mathrm{~mm}$ and proven studies of Walter Keba minute the effect of plant extract of the taxa on the cellular composition of Fusarium solani fungi studies showed an increase in the thickness of the fungal cell wall. Chemical analysis of the extract of the tax collector using the HPLC device. The plant extract of the tax collector contains phenolic and flavonoids, which are important materials to inhibit the growth of fungi.

Key words: Antagonistic activity, Trichorderma Spp., root rot pathogens,

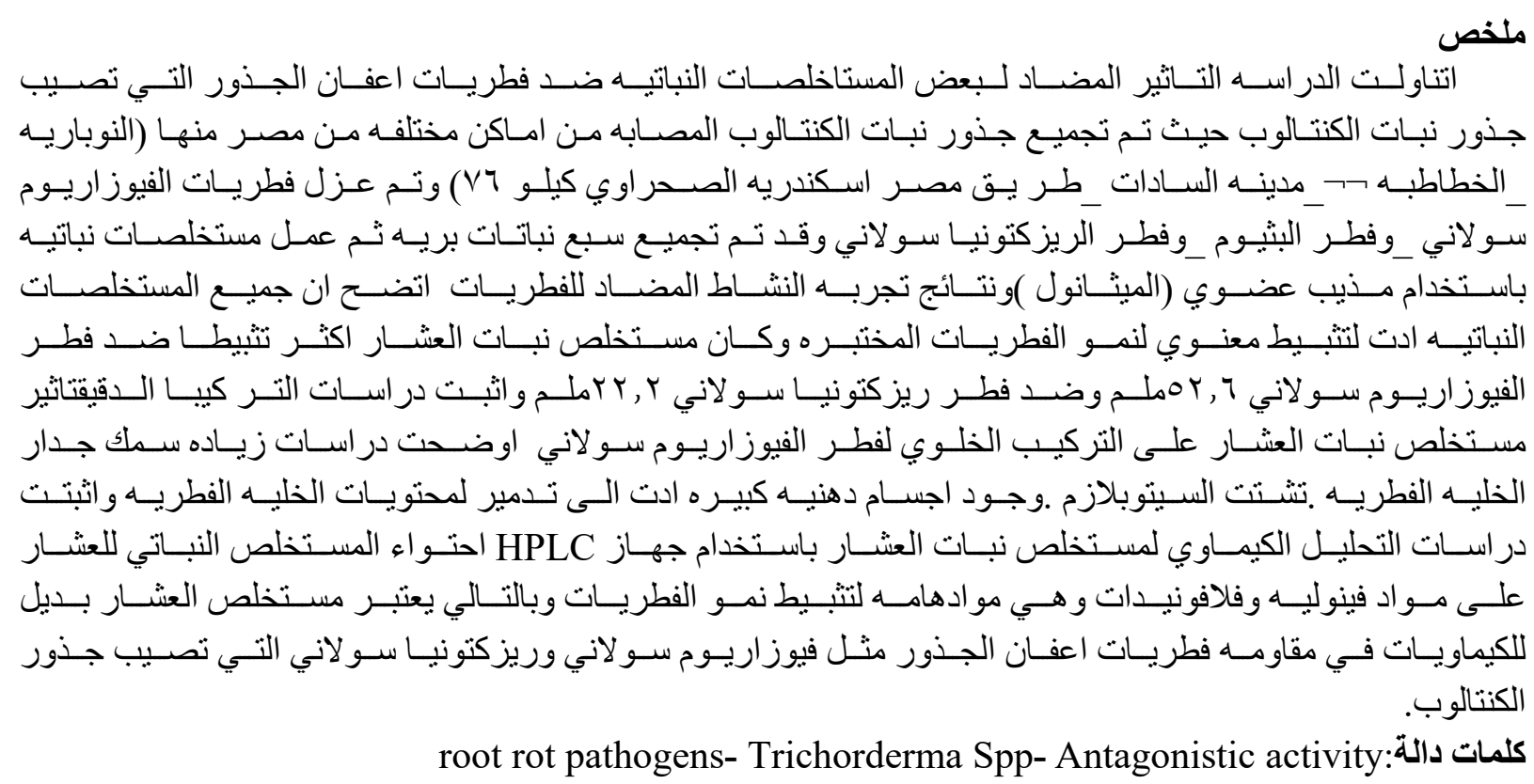

\section{INTRODUCTION}

Due to plant diseases every year nearly $10-20 \%$ of the total world food production was decreased and leads to loss of billions of dollars. Chemical control is offer nonspecific in its effect, may can cause killing beneficial organisms and it may have undesirable health and environmental pollution risk. Intensified used of fungicides has resulted in accumulation of toxic compound potentially hazardous to human and environment and also in the build up of resistance of the pathogens. In order to tackle 
these national and global problems, effective alternatives to chemical control are being employed. Biological control is nature friendly approach that uses specific micro-organisms, which interfere with plant protection. Biological control by an antagonism is a potential, no chemical and ecofriendly approach for managing plant diseases (Bailey et al., 2004).

Fusarium oxysporum is a soil borne fungal pathogen that attacks plants through roots at all stages of plant growth, causes major economic losses by inducing necrosis and wilting symptoms in many crop plants (Cotxarrera, et al., 2002). The disease caused by this fungus is characterized by wilted plants, yellowed leaves and root rot minimal or absent crop yield (Nemec et al., 1996). Fusarium wilt of tomato caused by Fusarium oxysporum $f$. sp. Lycopersici (FOL) is the major limiting factor in the production of tomato. The disease causes great losses, especially on the susceptible varieties of tomato especially when soil and air temperature are rather high during the warm season (Agrios, 1997, Mandal et al., 2009). The interaction between $F$. oxysporum and $F$. solani causes a root-rot disease complex that severely damages this important crop (Klotz, 1973).

Biological control of plant diseases is considered as one of the viable alternative methods to manage plant diseases (Barakat \& Al-Masri, 2005; Pal \& Gardener, 2006). The application of biological controls using antagonistic microorganisms has proved to be successful for controlling various plant diseases in many countries (Janisiewicz, 2000). Most of these studies were on the control of root and soil-borne plant pathogens and, to a lesser extent of foliar pathogens (Whipps \& Lumsden, 2001).

The antifungal activity of 36 plant aqueous extracts have been evaluated against F.oxysporuin, R.solani and B.cinerea in vitro testes and under greenhouse condition on watermelon and tomato plants (Elkaffash and Al-Menoufi,2003). They found that clove extract completely inhibited the mycelial growth of the three tested fungi whereas garlic extract suppressed the mycelial growth of F.oxyspornna and B.cinerea by $100 \%$ and R.solani by $88 \%$. In the same year, Dawood et al., (2003) evaluated 11 aqueous plant extracts for their antifungal activity against Fusarium solani, Fusarium oxysporum, Rhizoctonia solani, Sclerotinia sativa, Alternaria alternata, Aspergillus flavus, Botrytis cinerea, Sclerotium rolfsii and S.batiticola. They stated that Spearmint (Mentha viridis) extract had no effect on mycelial growth of any of the tested fungi.

The objective of this study was to evaluate the potential of the plant extracts of some wild plants in controlling the root rot fungi Rhizcoctonia solani and Fusarium solani which infected Cantaloupe plant under in vitro condition . 


\section{Materials \& Methods}

\subsection{PHYTOPATHOLOGICAL STUDIES}

\subsubsection{Sampling}

Naturally diseased Cantaloupe root showing wilting symptoms, Cantaloupe plants showing wilting and root rots were collected from different districts of Egypt namely Sadat city, Noberia, el kataba, and Alex. Egypt road K. 76. Collected samples were transfered to laboratory in plastic bags to be used in pathogen isolation.

\subsubsection{Phytopathogenic Fungi}

Isolation, identification and pathogenicity test were carried out for, Fusarium solani and and Rhizoctonia solani. The isolates were grown on potato - dextrose agar (PDA) medium (see-appendix) in petri dishes, then transferred to PDA slants and kept in refrigerator at $4^{\circ} \mathrm{C}$ as a stock cultures.

\subsubsection{Isolation, purification and identification of Fusarium solai}

Diseased cantaloupe plants showing different degrees of wilt disease were collected from different regions of, (Egypt Sadat city, Noberia, El kataba, and Alex. Egypt road K. 76).

The affected roots were washed thoroughly with running tap water and cut into small portions before immersing in Sodium hypochlorite $(5 \%$ chlorin) for one minute. The surface was washed with distilled water and finally dried between two sterilized filter papers. Then they were directly placed into Petri dishes containing potato dextrose agar medium (PDA) and incubated at $28^{\circ} \mathrm{C}$ for $3-5$ days. Examination was carried out when fungal growth appeared out from the incubated materials. All the isolated fungi were purified using single spore or the hyphal tip techniques suggested by Dhingra and Sinclair (1985). The purified fungi were identified according to their morphological features according to Booth (1985). Stock cultures were maintained on PDA slants and kept in a refrigerator at $5-10^{\circ} \mathrm{C}$ and were sub-cultured on fresh medium every 6-8 weeks.

\subsubsection{Isolation, purification and identification of Rhizoctonia solani}

The collected diseased cantalope roots showing damping-off disease were collected from different regions of washed in running tap water followed by sterile water. Using sterilized scalpel, roots were cut into small pieces $\left(1-2 \mathrm{~cm}^{2}\right)$. The pieces were then transferred into $0.1 \%$ hypochlorite solution (disinfectant solution) for 3 minutes for surface sterilization. Surface sterilized pieces were then washed several times with sterilized water to wash out the remaining disinfectant solution. The pieces were then dried on sterilized filter papers. Using sterilized forceps, dried pieces were then transferred into Petri dishes containing potato dextrose agar medium (PDA) supplemented with antibacterial agent (L-chloramphenicol $5 \mathrm{mg} \backslash \mathrm{L}$ and streptomycin sulphate $5 \mathrm{mg} \backslash \mathrm{L})$. The dishes were then incubated at $28 \mathrm{C}^{\circ}$. and checked for fungal growth two days later. The resulting isolates were purified using mycelium fragment. (Shabana, 1987). Pure cultures of the isolated fungi were identified according to the 
cultural properties, morphological and microscopical characteristics described by Domsch et al., (1980)

\subsection{COLLECTION OF WILD PLANTS}

Seven wild plants (Table 1) were collected from canal banks, fields and markets of various localities in El menofoia governorate and were taxonomically identified by Prof. Dr. Mohamed Fathy Azazy Surveys of Natural Resources Dept, Environmental Studies and Research Institute, University of Sadat City according to Tackholm (1974) and adopted according to Boulos (1999-2005).

Table (1): The collected wild plants

\begin{tabular}{|c|c|c|c|c|}
\hline No & Scientific name & Family & $\begin{array}{l}\text { Arabic } \\
\text { name }\end{array}$ & part used \\
\hline 1 & $\begin{array}{l}\text { Azadicachta indica } \\
\text { Adrjuss }\end{array}$ & Meliaceae & 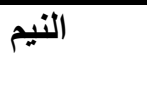 & Leaves \\
\hline 2 & $\begin{array}{ll}\text { Calotropis } & \text { procera } \\
\text { (Aiton)W.T. Aiton } & \end{array}$ & Asclepiedaceae & العشار & Leaves \\
\hline 3 & $\begin{array}{l}\text { Cymbopogon } \\
\text { (hochst) staps. }\end{array}$ & Poaceae & الحلفابر & Leaves \\
\hline 4 & Cyperus rotundus $\mathrm{L}$. & Cyperaceae & 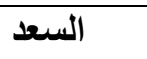 & Leaves \\
\hline 5 & $\begin{array}{ll}\text { Eucalyptus } & \text { rostrata } \\
\text { Schlecht } & \end{array}$ & Myrtaceae & الكافور & Leaves \\
\hline 6 & Nerium oleander L. & Apocynaceae & 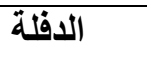 & Leaves \\
\hline 7 & Pluchea dioscoridis L. & Asteraceae & البرنوف & Leaves \\
\hline
\end{tabular}

\subsection{PREPARATION OF PLANT EXTRACTS}

Plant materials were dried in the shade at room temperature, ground using electrical mill into fine powder and extracted by soaking in methanol at the rate of $1: 3$ (w/v) for 48 hours.

The extracts were filtered through cheese cloth under a strong hand pressure and the solvent was dried under vaccum at $60-65 \mathrm{C}^{\circ}$ using a rotary evaporator. The extracted residue was dissolved in dimethyl sulfoxide $(1 \mathrm{mg} / \mathrm{ml})$. The crude extracts were preserved under refrigeration until use (Dawood et al.,2003).

1.4. Screening of different plant extracts for antifungal activities against the selected phytopathogenic fungi

Seven plant extracts (Table 1) were examined for their inhibitory activities against some selected phytopathogenic fungi by using agar diffusion technique (Deans and Ritchie,1987).

Dry potato dextrose agar plates were inoculated by spreading spore suspensions of constant fungal inoculum. In case of R.solani, discs were putted on the surface of plates because this fungus grow as mycelia or sclerotia. Wells were made in the inoculated potato dextrose agar plates for plant extracts and essential oils inoculation 
$(200 \mu)$. All plates were incubated at $26 \pm 2^{\circ} \mathrm{C}$ for 72 hours. The diameter of inhibition zones were determined for all tested fungi except R.solani, the radius of inhibition zones were measured.

\subsection{Phytochemical analysis by HPLC:}

The chemical composition of Sargssum species extract were performed in central labs unit, Faculty of Agriculture, Cairo University, Gizza, Egypt for detected phenolic, flavonoids and other active componds.

\subsection{Ultrastructure studies (T.E.M):}

The method described here is an example for fixation, contrastation and embedding only.For optimal results especially the fixation needs to be adapted to the investigated tissue. It is of major importance that the fixing agent is able to completely. Penetrate the specimen as soon as possible. For this reason only very small pieces of tissue $\left(\sim 1 \mathrm{~mm}^{3}\right)$ should be fixed if no perfusion fixation (fixative is directly infused into a larger vessel of a deeply anaesthized animal) should be possible. The preparation should be quick enough, i.e. 5 minutes after tissue does no longer receive oxygen, and it began to show first signs of degeneration of ultrastructures. Perfusion or immersion fixation of the tissue using a modified Karnovsky (1965) solution: $2.5 \%$ buffered glutaraldehyde $+2 \%$ paraformaldehyde in $0.1 \mathrm{M}$ sodium phosphate buffer $\mathrm{pH} 7.4$, leave tissue overnight at $4^{\circ} \mathrm{C}$, wash $3 \times 15$ minutes (min.) in $0.1 \mathrm{M}$ sodium phosphate buffer $+0.1 \mathrm{M}$ Sucrose, postfix $90 \mathrm{~min}$. in $2 \%$ sodium phosphate buffered osmium tetroxide $\mathrm{pH} 7.4$, wash 3 x $15 \mathrm{~min}$ in $0.1 \mathrm{M}$ sodium $\mathrm{p}$, after drying for $\sim 15 \mathrm{~min}$ sections may be investigated in a transmission electron microscope. Ultrathin sections were observed at $160 \mathrm{kV}$ using a JEOL JEM 2100 at Electron Microscopy Unit, Mansoura University, Egypt.

\subsection{Statistical analysis:}

All values represent the mean of triplicate determinations. Data were statistically analyzed by using one way analysis of variance (ANOVA) according to SPSS (1999). The least significant difference is abbreviated as LSD and measured at $P \leq 0.05$.

\section{RESULT}

\subsection{Psychopathological Studies}

2.1.1. Isolation, purification and identification of the causative organism of wilt disease (Fusarium solani)

The causative organism of wilt disease was isolated from diseased cantaloupe roots collected from different regions of Egypt namely Sadat city, Noberia, el kataba, and Alex. Egypt road K. 76. These isolates were identified as Fusarium solani (Fig.1) according to morphological and microscopic features (mycelial development and spore formation) according to Booth (1985). The identification was confirmed by Mycology Center, Assuit University as (Fusarium solani 9704 AUMC). 


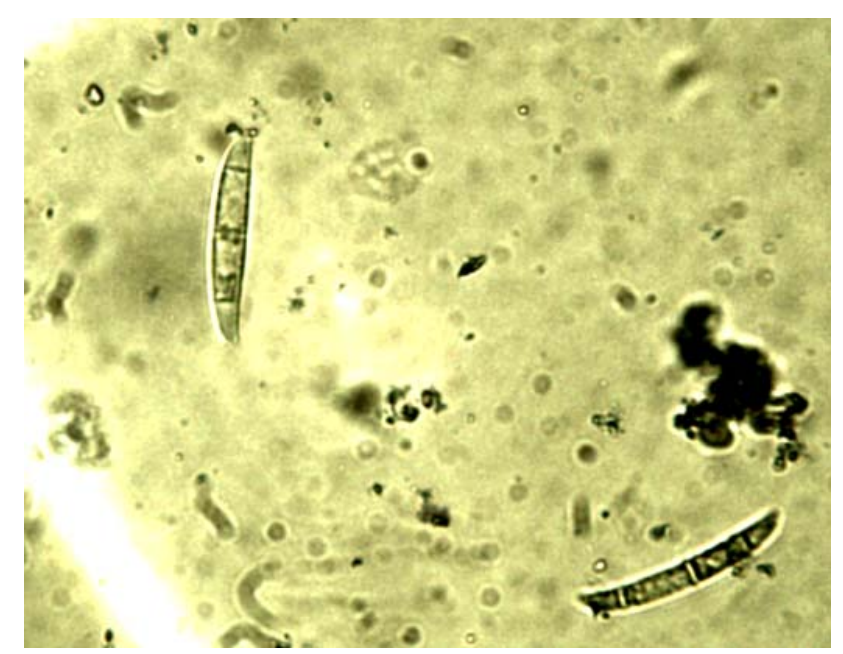

(1): Conidia of Fusarium solani (400x) light microscope

2.1.2. Isolation, purification and identification of the causative organism of dampingoff disease on bean (Rhizoctonia solani)

The causative organism of damping off disease was isolated from diseased cantaloupe roots which collected from different regions of Egypt namely Sadat city, Noberia, el kataba, and Alex. Egypt road K. 76. The isolates obtained were purified using mycelium fragment and these isolates were identified as Rhizoctonia solani (Fig.4) according to morphological and microscopical characteristics by Domsch et al., (1980). The identification was confirmed by Mycology Center, Assuit University as (Rhizoctonia solani 6590 AUMC).

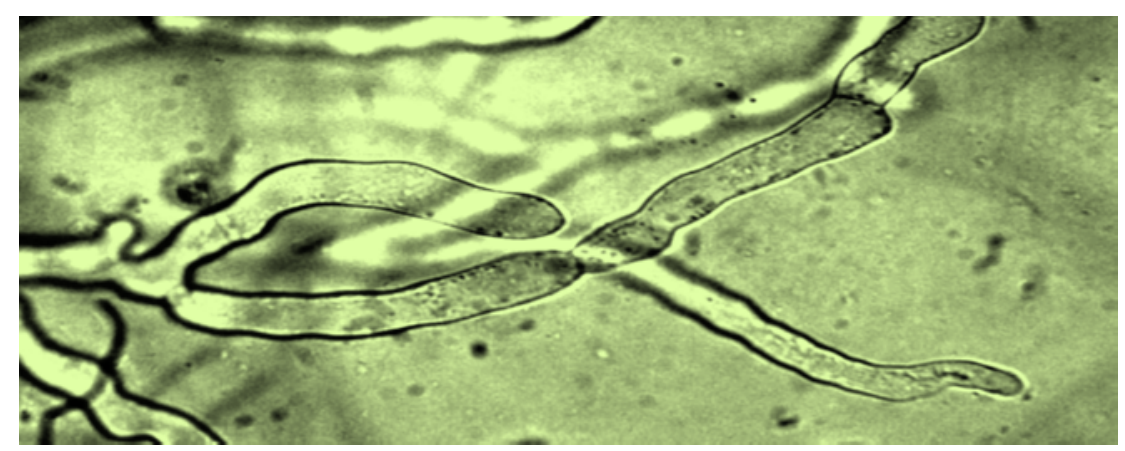

Fig (2): Mycelium of R.solani (400 x) light microscope

2.2. Screening of plant extracts for antifungal activities against Fusarium solani

Seven plant extracts were screened for their antifungal activities against Fusarium solani. They are arranged in Table (2) and Fig. (3) according their antifungal actitives. Calotropis procera was the most active plant extract against Fusarium solani followed by Azadicachta indica Adrjuss, Cymbopogon proximus (hochst) staps, Cyperus rotundus L., Eucalyptus rostrata Schlecht,Nerium oleander L. and Pluchea dioscoridis $L$. 
Table (2): Screening of plant extracts for antifungal activities against Fusarium solani

\begin{tabular}{|l|l|l|}
\hline NO & The plant extract & $\begin{array}{l}\text { Diameter of inhibition } \\
\text { zone }(\mathbf{m m}) \bullet\end{array}$ \\
\hline \hline & Control (DMSO) & 18.0 \\
\hline 1 & $\begin{array}{l}\text { Calotropis procera (Aiton) W.T. } \\
\text { Aiton }\end{array}$ & $52.6^{*}$ \\
\hline 2 & Azadicachta indica Adrjuss proximus (hochst) & $48.3^{*}$ \\
\hline 3 & $\begin{array}{l}\text { Cymbopogon } \\
\text { staps. }\end{array}$ & $41.5^{*}$ \\
\hline 4 & Cyperus rotundus L. & $38.5^{*}$ \\
\hline 5 & Eucalyptus rostrata Schlecht & $37.5^{*}$ \\
\hline 6 & Nerium oleander L. & $37.5^{*}$ \\
\hline 7 & Pluchea dioscoridis L. & $37.3^{*}$ \\
\hline
\end{tabular}

$\mathrm{LSD}=2.1$

-The recorded valued are the mean values of 3 replicates

* Significant

Non significant

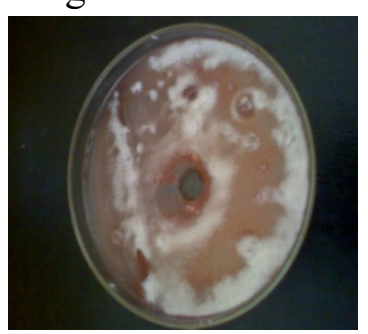

Control ( DSMO)

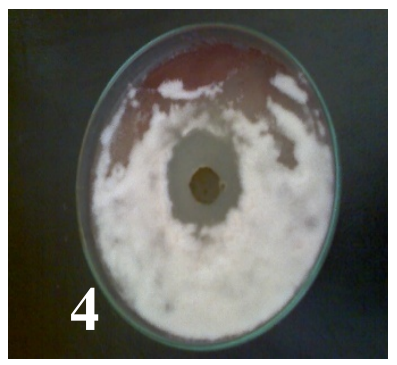

Cyperus rotundus

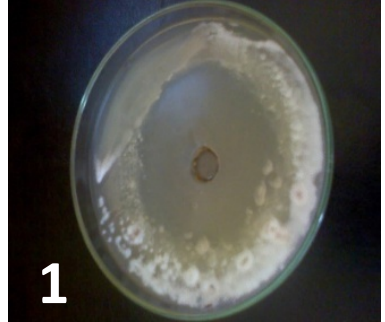

Calotropis procera

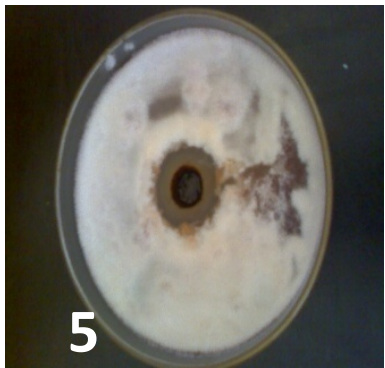

Eucalyptus

rostrata

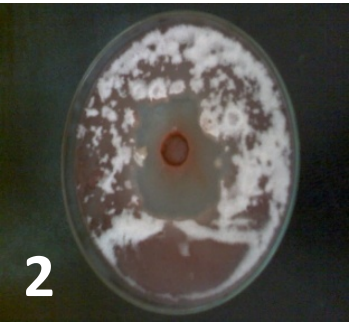

Azadicachta indica

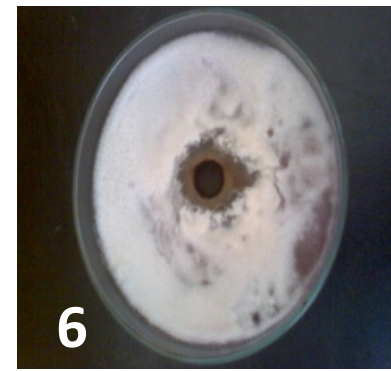

Nerium oleander

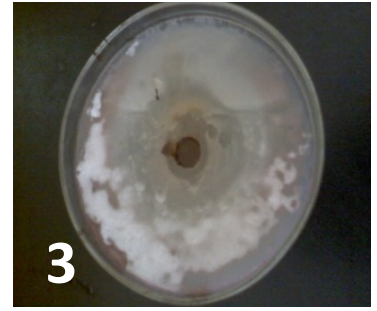

Cymbopogon proximus

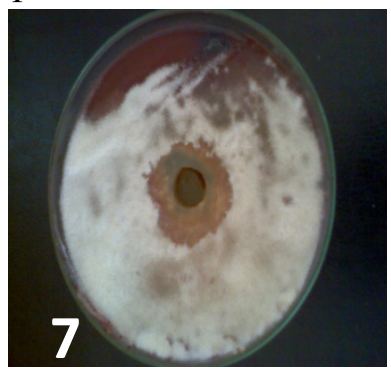

Pluchea

lioscoridis

Fig (3): Screening of plant extracts for antifungal activities against Fusarium solani

\subsection{Screening of plant extracts for antifungal activities against Rhizoctonia solani}

Data in Table (3) revealed that seven plant extracts were screened for their inhibitory activities against Rhizoctonia solani. They are arranged in Table 3) and Fig.(4) according to their inhibtorty activities. The plant extract of Calotropis procera was the most active against R.solani followed by Eucalyptus rostrata Schlecht, 
Azadicachta indica Adrjuss, Cyperus rotundus L., Nerium oleander L., Cymbopogon proximus (hochst) staps. and Pluchea dioscoridis L. respectively.

Table (3): Screening of plant extracts for antifungal activities against Rhizoctonia solani

\begin{tabular}{|l|l|l|}
\hline $\begin{array}{l}\mathbf{N} \\
\mathbf{o}\end{array}$ & Plant extract & $\begin{array}{l}\text { Radius of inhibition zone } \\
(\mathbf{m m})^{\bullet}\end{array}$ \\
\hline & Control (DMSO) & 4.0 \\
\hline 1 & $\begin{array}{l}\text { Calotropis procera (Aiton) W.T. } \\
\text { Aiton }\end{array}$ & $22.2^{*}$ \\
\hline 2 & Eucalyptus rostrata Schlecht & $20.1^{*}$ \\
\hline 3 & Azadicachta indica Adrjuss & $19.8^{*}$ \\
\hline 4 & Cyperus rotundus L. & $14.8^{*}$ \\
\hline 5 & Nerium oleander L. & $14.6^{*}$ \\
\hline 6 & $\begin{array}{l}\text { Cymbopogon proximus (hochst) } \\
\text { staps. }\end{array}$ & $11.7^{*}$ \\
\hline 7 & Pluchea dioscoridis L. & $11.5^{*}$ \\
\hline
\end{tabular}

$\mathrm{LSD}=0.1$

-The recorded valued are the mean values of 3 replicates

* Significant

Non significant

Fig (4): Screening of plant extracts for antifungal activities against Rhizoctonia solani

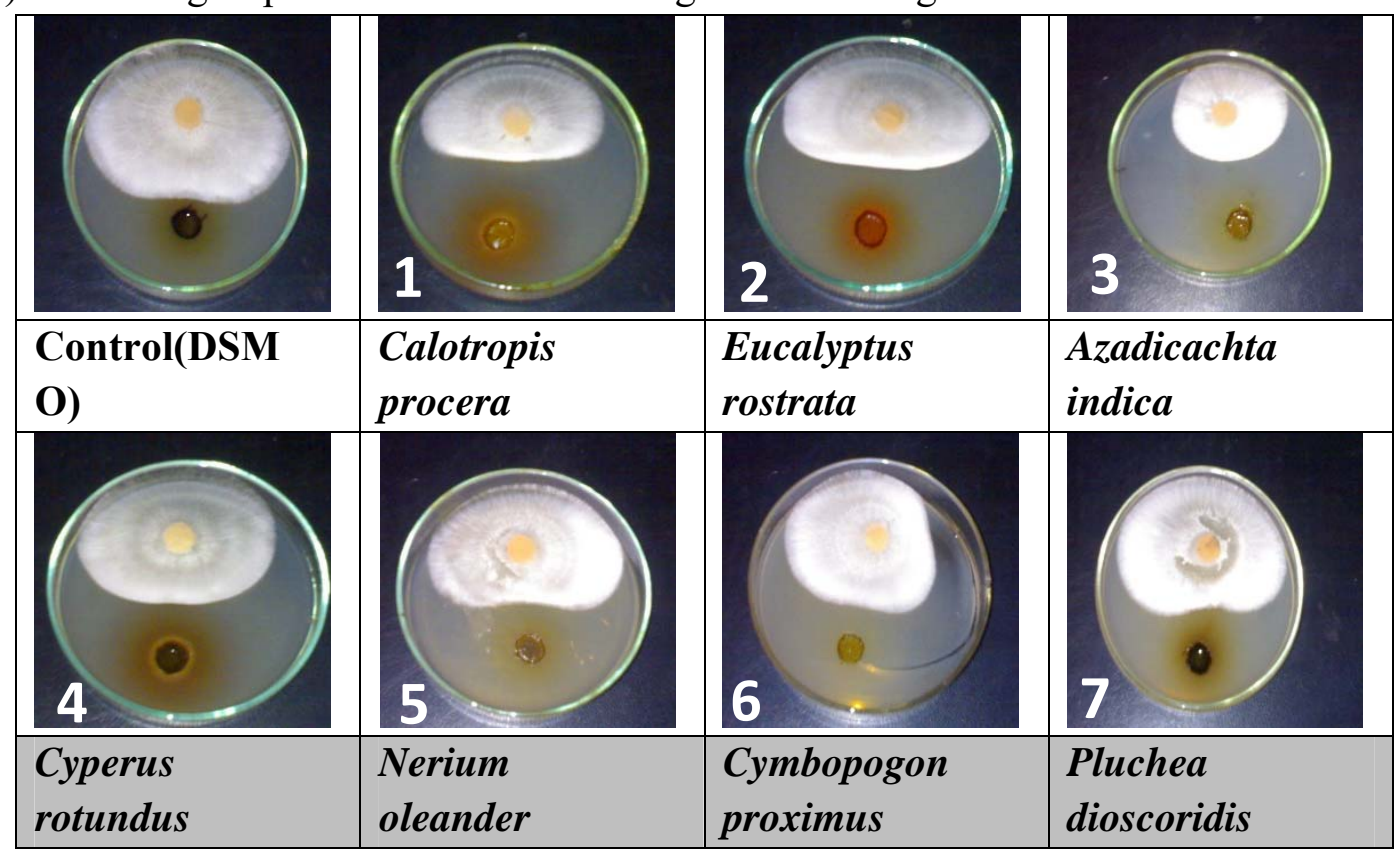

2.4. Transmission electron micrographs showing the effect of plant extract of calotropis prcera on Fusarium solani.

A: fusarium solani hypha grown on medium lacking plant extract of calotropis prcera. A cell of fusarium solani surrounded by a thin wall (W) and the cytoplasm (Cy) 
contains numerous organelles such as mitochondria (M). Note an electron-dense plasmalemma (arrow). Scale bar $=0.5 \mu \mathrm{m}$ (cited from Baka et al., 2002).

$\mathrm{B}$ and $\mathrm{C}$ : Fusarium solani hypha grown on medium containing plant extract of calotropis prcera at concentration of $0.3 \%$. Fusarium solani cell show a thickening wall (w), disintegration of cytoplasm (Cy). Note large lipid bodies (L), vacuoles (v) and not recognized plasma membrane. Scale bar $=0.5 \mu \mathrm{m}$.
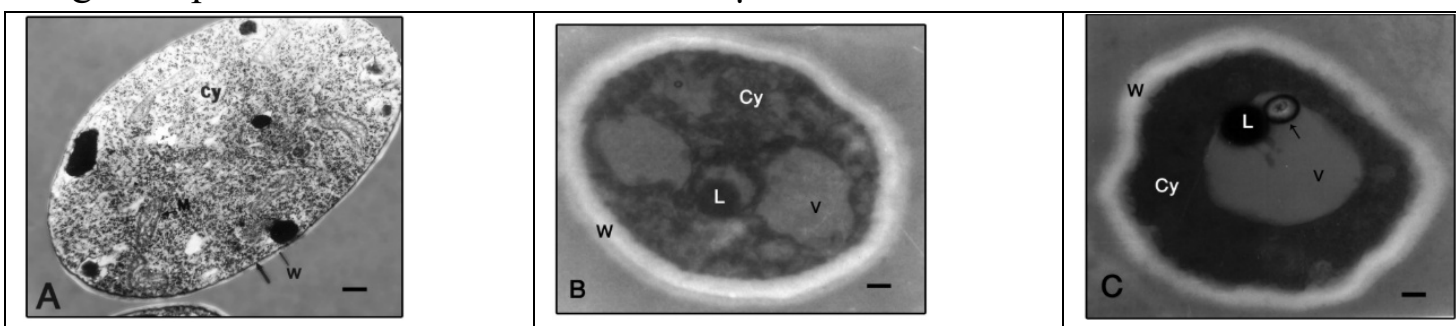

Fig. (5) Transmission electron micrographs showing the effect of plant extract of calotropis prcera on Fusarium solani.

2.5. Phytochemical analysis by HPLC:

The results in Table (4) showed Phytochemical analysis of calotropis prcera extract showed presence of phenolic compound and flavonoids which responsible for antifungal activites.

Table (4): Phytochemical analysis by HPLC:

\begin{tabular}{|l|l|}
\hline Compound & conc. $\mathbf{( u g} / \mathbf{g}$ ) \\
\hline Gallic acid & 0.000 \\
\hline Protocatechuic acid & 15.919 \\
\hline$p$-hydroxybenzoic acid & 29.767 \\
\hline Gentisic acid & 0.000 \\
\hline Catechin & 134.522 \\
\hline Chlorogenic acid & 31.668 \\
\hline Caffeic acid & 0.000 \\
\hline Syringic acid & 8.148 \\
\hline Vanillic acid & 5.080 \\
\hline Ferulic acid & 200.160 \\
\hline Sinapic acid & 115.025 \\
\hline$p$-coumaric acid & 0.000 \\
\hline Rutin & 183.061 \\
\hline Apigenin-7-glucoside & 0.000 \\
\hline Rosmarinic acid & 0.000 \\
\hline Cinnamic acid & 5.673 \\
\hline Quercetin & 0.000 \\
\hline Kaempferol & 106.245 \\
\hline Chrysin & 0.000 \\
\hline
\end{tabular}

Discu Thus, our study was planned to replace the undesirable and unsafe chemical control by another effective, inexpensive and safe options for control of some root rot diseases in Cantaloupe Several strategies were used for biological control of 
plant pathogens by using plant extracts (Assadi and Behroozine,1987 Natural plant extracts may provide an alternative to chemicals for controlling plant disease (Farag et al., 1989).

The screening of antifungal activity of seven_plant extracts against phytopathogenic fungi;, $F$ solani, R.solani, showed that plant extracts have antifungal activities against the tested phytopahogenic fungi. Among all plant extracts tested the plant extract of calotropis procaera proved to be the highest most effective growth inhibitor for all the tested phytopathogenic fungi. Also the results revealed that the other plant extracts have high antifungal activities against the tested phytopathogenic fungi. These results were in agreement with that of Wilson et al.,(1997) who tested extracts from 345 plants for their antifungal activities against Botrytis cinerea. They found that among the 345 plant extracts tested, 13 showed high levels of antifungal activities, with species of Allium predominating.

Also, Carcia and Lawas (1990) studied the antifungal activity of the crude water extract of 127 plant species against R.solani and they found that garlic extract (Allium sativum was the most effstive one Mahmoud et al.,(2004), reported that, the plant extracts of Ipomoea carnea, Eucalyptus citriodora, Cuminum cyminum, Allium sativum and Hyocyampus muticus have antifungal activities against Botrytis fabae and showed that the plant extracts of Eucalyptus citriodora and Ipomoea carnea have high inhibition zones against B.fabae also have high ability to decrease percentage of spore germination of B.fabae.

The antifungal activities of plant extracts may be attributed to the plant contents of secondary metabolites (e.g. phenolic, alkaloids, flavonoids, and terpenoids) that could adversely influence pathogen growth and development (Cowan,1999). Some plants impact on the growth and or development of others by releasing various chemical compounds called allelopathy (Jadhav et al.,1997). 
3. Also, Ranjan et al., (1991) studied the activity of 15 plant extracts on aflatoxin production and growth of Asp. flavus. They observed that extract of Artemisia indica and other 5 plants inhibited the production of aflatoxins B1 and B2 by more than 50\% .Moreover, Ismail (1998) tested the antifungal activity of aqueous extracts of 7 plants against R.solani and F.oxysporum . Artemisia Judaica had a moderate inhibition effect on the linear growth of the tested fungi. In the present work, the transmission electron microscope (TEM) examination of sections from $f$ solani grown in the presence of $0.3 \%$ plant extract of calotrops procera showed a pronounced cellular disorganization of the fungus. These changes include distorted cell walls, no discernible organelles, increase of lipid bodies and vacuoles and disintegration of the cytoplasm. These results were in agreement with that of Bianchi et al., (1997) who reported that transmission and scanning electron microscopy revealed cytomorphological alterations of the hyphae of Collectotrichum lindemuthianum, Rhizoctontia solani and Fusarium solani treated with garlic extract Nakamura et al.,(2004) reported that the analysis of the ultrastructure of yeast cells treated with the essential oil of Ocimum gratissum revealed changes in the cell wall and in the morphology of some subcellular organelles and also reported that the essential oil of Ocimum gratissum has antifungal activities and eugenol is the main constituent of this essential oil and is though to be mainly responsible for the antifungal effect.ssion:

4. Assadi, P. and Behroozin, M. (1987). The effect of bulb extract of onion and garlic on the mycelial growth of Fusariurn spp. and Sclerotium cepivorum. Iranian Journal of Plant Pathology 23: 1-6.

5. Farag R. S.; Daw, Z. Y. and Abo-Raya, S. H. (1989). Influence of some spice essential oils on Aspergillus parasiticus growth and production of aflatoxins in a synthetic medium. J. Food Sci. 54:74- 76.

6. Wilson, .R. (1937). The chocolate spot disease of beans (Vicia faba L. caused by Botrytis cinerea pers. Ann. Appl. Biol.; 24:258.

7. Wilson, C. L., Solar, J. M., El Ghaout, A., Wisniewski, M. E., (1997). Rapid evaluation of plant extracts and essential oils for antifungal activity against Botrytis cinerea. Plant Disease 81, 204-210.

8. Carcia, R. P., and Lawas, M. V. P. (1990). Note: Potential plant extracts for the control of Azolla fungal pathogens. Philippine Agriculturist 73: 343-348.

9. Cowan, M. M. (1999). Plant products as antimicrobial agents. Clinical Microbiology Reviews Jadhav P. S, Malik N. G. and Chavan P. D. (1997). Allelopathic effects of Ipomoea carnea subsp. fistulosa on growth of Ranjan, K. S., Gajendra, P., and Sinha, A. K. (1991). Evaluation of some bitter plant extracts against aflatoxin production and growth of Aspergillusflavus. National Academy Science Letters 14: 241-243.

10. wheat rice sorghum and kidneybean. Allelopathy Ismail, A. E. A. (1998). Control of soil-borne fungi causing root rot and wilt of tomato plant by some plant extracts. J. Agric. Sci. Mansoura Univ. 23: 1081-1091. 
11. Bianchi, A., Zambonelli, A., Zechini D'Aulerio, A., and Bellesia, F. (1997). Ultrastructural studies of the effects of Allium sativum on phytopathogenic fungi in vitro. Plant Dis. 81: 1241-1246. Nakamura, C . V.; Kelly, I. Ligia , C. F. and Benedito , P .D .E. (2004). In vitro activity of essential oil from Ocimum gratissimum L. against four candida species . Research in microbiology 155 (2004) 579-586.

12. Booth, C. (1985). The genus Fusarium. Commonwealth Mycological Institute, Kew. Surrey, England, 237 pp.

13. Dennis C, Webester J (1971a). Antagonistic properties of species group of Trichoderma I. Production of volatile antibiotics. Trans. Brit. Mycol. Soc. 57: 4148.

- Bailey, D.J., Kleczkowski, A., Gilligan, C.A.,(2004). Epidemiological dynamics and the efficiency of biological control of soil-borne disease during consecutive epidemics in a controlled environment. New Phytol ., 161:5 Cotxarrera, L., M.I. Trillas-Gay, C. Steinberg and C. Alabouvette, (2002). Use of sewage sludge compost and Trichoderma asperellum isolates to suppress Fusarium wilt of tomato. Soil Biology and Biochemistry, 34: 467-476.

- 69-576. Nemec S., Datnoff L.E., Strandberg J., (1996). Efficacy of biocontrol in planting mixes to colonize plant roots and control root diseases of vegetables and citrus. Crop Protection 15: 735-742.

- Agrios, G.N. (1997). Plant pathology. Academic Press, New York, USA.

- Klotz L.J., (1973). Color Handbook of Citrus Disease. University of California, Division of Agricultural Science, Berkeley, CA, USA.

14. References 